\title{
Why aren't medical devices regulated like drugs?
}

\author{
Fiona Godlee editor in chief
}

The BMJ

How much do you know about the safety and effectiveness of the implanted devices your patients are offered? You may assume that pacemakers, neurostimulators, joint prostheses, and breast implants have been tested rigorously before being licensed for widespread use. But this week a major international investigation, involving 59 organisations and including The $B M J$, finds device regulation unfit to protect patients from harm (https://www.icij.org/investigations/implant-files; doi:10.1136/ bmj.k4999, doi:10.1136/bmj.k5010, doi:10.1136/bmj.k4917, doi:10.1136/bmj.k5026).

Regulation in Europe is especially lax and shrouded in secrecy, finds this year long investigation by the International Consortium of Investigative Journalists. Intense industry lobbying has dissuaded lawmakers from tighter oversight, leaving Europe's citizens prey to inadequately tested devices and poor access to information on their safety.

Manufacturers have claimed that Europe's rapid licensing procedures protect innovation and investment while incurring no added risk to patients. But research published in The BMJ found a threefold greater rate of safety alerts and recalls for devices registered in Europe than for those registered in the US (doi:10.1136/bmj.i3323). Sources of harm to patients include a lung sealant that leaked, breast implants that went rancid, implanted pacemakers that stopped working, and deep brain stimulators that had to be removed. Reports of these malfunctions and injuries are currently confidential, but the investigation found that their number has tripled in the past nine years in many European countries.

Europe has no agency to oversee the licensing of medical devices equivalent to the European Medicines Agency, which requires evidence of effectiveness and safety before new drugs can be marketed. Attempts to establish such an agency were thwarted by industry lobbying that the MEP leading the effort called the worst she had ever seen.

Hope for greater transparency was pinned on an upgraded computer system, Eudamed. But this now looks unlikely to make incident reports publicly available, because the European Commission doesn't want to scare patients. One researcher calls this "expropriation of information belonging to patients." Without it, how can they and their doctors decide which implants to choose and which to avoid? Device regulation is not fit for purpose. Our hope is that this investigation will bring renewed pressure for reform.

\section{New columnists and Christmas appeal}

This week sees the first of the new regular columnists in our refreshed line-up. Joining David Oliver, who presents his top healthcare words of 2018 (doi:10.1136/bmj.k4883), you'll find Clare Gerada writing on resilience (doi:10.1136/bmj.k4974) and Helen Salisbury on what GPs should stop doing (doi:10. 1136/bmj.k4976). Next week we'll hear from the consultant diabetologist Partha Kar and, in the new year, ENT surgeon Gabriel Weston.

Finally, for our Christmas charity appeal this year we support Doctors of the World (doi:10.1136/bmj.k4993). With 3000 volunteers in more than 80 countries, it works to ensure access to healthcare for the world's most vulnerable and forgotten people, including in war torn Yemen. The charity intends to move its only permanent UK clinic to larger premises in London and hopes to open a second clinic in Birmingham. Donations from $B M J$ readers can make these plans a reality. Please, as always, give generously. 